\title{
Persistence of currency crises: evidence to Asian and subprime crisis
}

\author{
Nadhem Selmi* and Nejib Hachicha
}

Department of Quantitative Methods, Faculty of economics sciences and management, Sfax University, Tunisia

\begin{tabular}{l}
\hline C H R O N I C L E \\
\hline Article history: \\
Received October 28, 2014 \\
Received in revised format 15 \\
January 2015 \\
Accepted 27 January 2015 \\
Available online \\
January 282015 \\
\hline Keywords: \\
Long Memory \\
Exact Local Whittle \\
Financial crisis \\
\hline
\end{tabular}
A B S T R A C T

This paper investigates the contribution of index of the speculative pressure to the persistence of currency crises by identifying the determinants of high persistence in the exchange market pressure index for twenty countries affected by crisis. The Exact Local Whittle model is utilized to identify the high persistence of crisis. Our results show the persistence of the currency crisis.

\section{Introduction}

Since the study of Hurst (1951), time series has exhibited a long-term dependency structure and it has become an important research topic in the economic and financial market. The transmission of financial crises between countries which do not have direct economic linkages with the contaminating country is caused by the signals of vulnerability shown by the crisis, which shows persistent of shocks. This transmission, therefore, provides opportunities for a successful speculative attack in a country with a similar character. The study of the Asian crisis shows that the reasoning of the monetary authorities is made in accordance with teaching of the model of second generation1 crisis (Flood \& Marion, 1996). Indeed, a country with a similar macroeconomic situation is not able to defend its exchange rates. Thus, a country in crisis provides new information on arbitration risk and return about the risk-return trade in another country. This explains the irrational flight of capitals in some areas.

\footnotetext{
${ }^{1}$ According to Obstfeld (1994), this crisis is a self-fulfilling crisis, without significant changes in fundamentals.
}

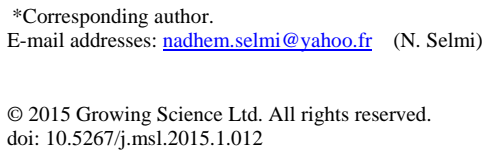


Since the study of Hurst (1951), the time series may have shown a long-term dependency structure, they have become an important research topic in economics and finance. Several form series with long memory is characterized by an autocorrelation function, which decays slowly when the number of delays increases.

This paper is divided into three sections: the first one describes the crisis in the emerging countries, the second analyzes the econometric methodology finally, and the third section presents the empirical results.

\section{Crises in the emerging countries: origins and causes}

The Asian crisis has its actual origins in the collapse of the Thai baht on July 2, 1997. It is the largest economic crisis since the Great Depression. Its hit has affected successfully most countries successfully succession in several the region such as Malaysia, Philippines, Indonesia and South Korea. To a less extent, Hong Kong, Singapore and Taiwan, it also spread to Latin America, Russia and other countries. The Thai crisis rapidly spread to other neighboring countries with similar growth through contagion. This crisis gives a character of the third generation (Artus, 2000; Cartapanis, 2003).

In March 1997, the Thai baht fell. This drop was particularly caused by the altitudes of the residents wishing to hedge their debts in foreign currencies. To address this situation, the Thai central bank discounted a portion of its reserves forward sales in dollar. After reporting the losses of the major Thai financial institutions, monetary authorities fluctuated, on one hand, the value of the baht was devalued rapidly.

The currency peg to the dollar has become a contagious phenomenon when in July 8, Malaysia abandoned its anchor followed the Philippines on July 11, however, Indonesia extended its fluctuation margins from $8 \%$ to $12 \%$. At the end of 1997, these currencies were depreciated from 35 to $80 \%$ in a situation characterized by a massive reflux of international capital outside Asia (Radelet \& Sachs, 1998). Several Asian currencies were affected by the depreciation of the baht, for instance, the Malaysian ringgit then the Indonesian rupiah which underwent a large devaluation. Besides, the Hong Kong dollar was hit in October 1997. Gravereau \& Trauman (2001) found that there was a double effect of currency depreciation in the short term. Since the debts in dollar and private debts were not played back, especially those with a short-term composition and a maturity of approximately one year, the debt in South Korea, Thailand, Indonesia and Malaysia reached to 100, 70, 56 and 25 billion dollars, respectively. Other countries such as Russia, in August 1998 and Brazil at the end of this year were the scenes of financial crises after the Asian crisis. The subprime crisis is a global financial one which started in 2006 by a crash of the subprime mortgages in the United States. It was the cause of the 20072008 financial crises worsened in 2008.

Sachs et al. (1996) used the index of the speculative pressure-dependent on the exchange rates. The crisis index is the average variation in the exchange rates associated with the negative percentage of the change in the international reserves. The upper value of this index represents the most severe crisis. According to Sachs et al. (1996), a currency crisis is defined by the depreciation of the exchange rate where a power of the monetary authorities regulates in the foreign exchange reserves to defend the currency. More real depreciation, the higher foreign exchange reserves are high. The crisis index can be presented as follows:

$$
I_{\text {Crisis }}=\left[\frac{\ln \left(\frac{R E R_{t}}{R E R_{t-1}}\right)}{\sigma_{R E R}}\right]-\left[\frac{\ln \left(\frac{I S_{t}}{I S_{t-1}}\right)}{\sigma_{I S}}\right]
$$


where $R E R_{t}, R E R_{t-1}$ designate the real exchange rate at times $t$ and $t-1$ and $I S_{t}$ and $I S_{t-1}$ are the international reserves at times $t$ and $t-1 . \sigma_{R E R}$ and $\sigma_{I S}$ are the standard deviations of the real exchange rate and the international reserve currency, respectively.

\section{Econometric Methodology}

Generally the modelling of the time series is based on the assumption of stationary (no unit root). The differentiation of the time series is necessary to apply the modelling approach initiated by Box and Jenkins (modelling with ARMA (p, q)) when we have a non-stationary process, but a problem of overdifferentiation may to be taken place since the degree of differentiation " $d$ " in the case of ARIMA model is considered a natural number.

To resolve this problem, Granger and Joyeux (1980) and Hosking (1981) introduced an intermediary case where the degree of integration " $d$ " is fractional. The process of long-term dependence is more accurate than those of Class $I(0)$ and $I(1)$. For $0<d<\frac{1}{2}$, is called stationary processes with a hyperbolic in decline of the function of the auto-correlations, indicating a long memory or long-term dependency.

\subsection{Exact Local Whittle Estimator (ELW)}

The other class of semi-parametric frequency domain estimators follows the local Whittle approach suggested by Künsch (1987) analyzed by Robinson (1995) called a Gaussian semi-parametric estimator and it is attractive because of its likelihood interpretation, nice asymptotic possessions and very class assumptions. The LW estimator is distinct to maximize of the (local Whittle likelihood) purpose:

$$
Q(g, d)=-\frac{1}{m} \sum_{j=1}^{m}\left[\log \left(g \lambda^{-2 d}\right)+\frac{I\left(\lambda_{j}\right)}{g \lambda^{-2 d}}{ }_{j}\right]
$$

where $m=m(T)$ which is a bandwidth number tends to infinity as $T \rightarrow \infty$ except at a slower speed than $T . I(\lambda)=\frac{1}{2 \pi T}\left|\sum_{t=1}^{T} y_{t} e^{i t \lambda}\right|^{2}$ is the periodogram of $y_{t}, g_{x}(\lambda)$ is the spectral density of $y_{t}$, $\lambda_{j}=\frac{2 \pi j}{n}$, and $j=1, \ldots, n$.

One disadvantage compared with log-periodogram estimation is that a statistical optimization is needed. On the other hand, the assumptions underlying this estimator are weaker than the logperiodogram regression (LPR) estimator. Robinson (1995) showed that while $d \in\left(-\frac{1}{2}, \frac{1}{2}\right)$ we have

$$
\sqrt{m}\left(\hat{d}_{L W}-d\right) \stackrel{d}{\rightarrow} N(0,1 / 4) .
$$

Therefore, the asymptotic distribution is extremely simple, facilitating easy asymptotic inference, and in particular the estimator is more efficient than the LPR estimator. The ranges of reliability and asymptotic normality for the LW estimator have been shown by Velasco (1999) and by Phillips \& Shimotsu (2005) to be the same as those of the LPR estimator.

An exact local Whittle (ELW) estimator has been planned by Shimotsu and Phillips (2005) that avoids some of the approximations in the divergence of the LW estimator and is valid for any value of $d$. The ELW estimator replaces the object function (3) by the following, 


$$
Q_{E}(g, d)=-\frac{1}{m} \sum_{j=1}^{m}\left[\log \left(g \lambda^{-2 d}\right)+\frac{I_{\Delta^{d} X}\left(\lambda_{j}\right)}{g}\right],
$$

where $I_{\Delta^{d} X}(\lambda)=\frac{1}{2 \pi T}\left|\sum_{t=1}^{T}\left(\Delta^{d} y_{t}\right) e^{i t \lambda}\right|^{2}$ is the periodogram of $\Delta^{d} y_{t}$. The ELW estimator assure Eq. (3) for any value of $d$ and is thus not restricted to any exacting range of $d$ values, but it is limited to zeromean processes.

In addition, Shimotsu (2002) projected the feasible ELW (FELW) estimator. Andrews and Sun (2004) proposed a generalization of the local Whittle estimator, the local polynomial Whittle (LPW) estimator of $d$ designed for $d \in\left(-\frac{1}{2}, \frac{1}{2}\right)$.

For both the log-periodogram regression technique and the local Whittle approach, the alternatives of bandwidth parameter $m$ are very significant. Results on optimal, minimizing the sum mean squared error, choice of bandwidth for the log-periodogram regression have been interpreted derived by Hurvich et al. (1998), and results of the local Whittle approach have been derived by Henry \& Robinson (1996). In both cases, the optimal bandwidth is said to be multiplied by $T^{0.8}$, where the multiplicative stable depends on the smoothness of the spectral density near the source, i.e., on the short-run dynamics of the procedure.

\subsection{Tests of long memory}

a-Lo test

If $Q_{T} \in[0.809,1.862]$, there is no long memory with a risk of 0.05 .

\section{$b-G P H$ test}

The GPH statistic is given by

$$
G P H_{T}=\hat{d}\left(\frac{\pi^{2}}{6 \sum_{j=1}^{m}\left(Z_{j}-\bar{Z}\right)^{2}}\right)^{-\frac{1}{2}} \text {. }
$$

Under $\mathrm{H}_{0}: G P H_{T} \rightarrow N(0,1)$ so if $\left|G P H_{T}\right|<1.96$, there is no long memory with a risk of $\alpha=0.05$. If $\hat{H}=\hat{d}+\frac{1}{2}$ that GPH imposed is the estimator of $\mathrm{H}$ we consider $R 1_{T}=2 \sqrt{6 m}\left(\hat{H}-\frac{1}{2}\right) / \pi$. If $\hat{H}$ is the Gaussian semi-parametric estimator of $\mathrm{H}$, we consider $R 1_{T}=2 \sqrt{m}\left(\hat{H}-\frac{1}{2}\right)$. Therefore if $\max \left(R 1_{T}, R 2_{T}\right)<1.96$, no long memory exists with a risk $\alpha=0.05$. The failure of the test procedure standard stationary (ADF, KPSS and PP) is explained by the instability of the crisis index and thus the possible break points enable us to use a unit root test that takes into account the structural changes.

The unit root test with two structural breaks of Strazicich and Lee (2003) is important. The central idea of this test is the interaction between structural breaks and the unit roots. Lee and Strazicich (2003) studied the unit root test of the Lagrange multiplier introduced by Schmidt and Phillips (1992) by 
applying the possibility of two endogenous breaks. To get the statistics Lagrange multiplier of the null hypothesis of the existence of a stochastic trend, Lee and Strazicich (2003) made the following regression:

$$
y_{t}=\mu+\mu D M U_{t}+\beta \text { trend }_{t}+\gamma D(T B)_{t}+\alpha y_{t-1}+\varphi d y_{t-1}+\varepsilon_{t},
$$

where

$D(T B): \quad(T B=$ date of structural change) $=1$ if $t=T B 1$ and 0 , otherwise. trend: linear trend and $\mathrm{DMU}=1$ if $\mathrm{t}=0$ and $\mathrm{TB}$ elsewhere.

In addition, $\mu, \theta, \beta, \gamma$ and $\varphi d$ are parameters to estimate, $\varepsilon_{t}$ is the error term. This test therefore allows the simultaneous existence of two breaks in both the series level and the deterministic trend. The test of the null hypothesis of the presence of a unit root is then defined by testing $H_{0}: \alpha=0$ vs $H_{1}: \alpha<0$ and the statistic test (Statistics Student's t). The location of the two dates of breaks $\left(\alpha_{j}=\frac{T_{B j}}{T}, j=1,2\right)$ occurs endogenously by minimizing the statistical Student's $t$ for all values of $L M_{t}=I n f_{\alpha}(t(\alpha))$. Lee and Strazicich (2003) determined the critical values of the test depending on the situation of structural changes $\alpha(j)$ in the sample.

\section{Empirical study}

The sample of the countries chosen in our empirical study includes 20 countries $^{2}, 5$ in East Asia, seven in Latin American countries and the G8 countries, as well as the mortgage price index for the United States. The composition of this sample is explained by the fact that it includes most countries which the most severe experienced financial crises in the last decade.

We chose several crisis episodes of crises of the 1990s: the 1997 Asian crisis, the 1998 Russian crisis, the crisis in Brazil in 1999, the crises in Turkey and Argentina in 2001, the crisis in Uruguay in 2002 and the subprime crisis in 2006. Indeed, these episodes were the cause of the debates have regarding to contagion. Thus, information on 20 countries was observed over several episodes of crisis. The data are gathered from the International Financial Statistics (IFS). We used a sample of countries that are affected by crises in different episodes.

\section{Table 1}

Periods of crisis

\begin{tabular}{lll}
\hline Countries & Beginning of the crisis & End of crisis \\
\hline Argentina & January 02 & December 02 \\
Brazil & January 99 & December 99 \\
South Korea & November 97 & June 98 \\
Hong-Kong & November 97 & August 98 \\
Indonisia & August 97 & June 98 \\
Malaysia & July 97 & June 98 \\
Russia & August 98 & December 99 \\
Thaïland & July 97 & June 98 \\
Turkey & April 01 & October 01 \\
Uruguay & March 02 & October 03 \\
US & October 06 & June 09 \\
UK & November 07 & July 08 \\
\hline
\end{tabular}

\footnotetext{
${ }^{2}$ Germany, Argentina, Brazil, Canada, South Korea, the United States, France, Hong Kong, Italy, Indonesia, Japan, Malaysia, Mexico, Russia, Singapore, Taiwan, Thailand, Turkey, the United Kingdom and Uruguay.
} 
The phenomenon of the crisis propagation is well illustrated by the change in the index of the speculative pressure across the countries affected by the crises. The crisis hit Mexico, spread to Thailand and Argentina, and later to Brazil and the Philippines and did the global of subprime crisis, which is a good illustration of the movement of the HPI during this crisis (Selmi \& Hachicha, 2010). The crisis periods found of are similar to those of the Asian crises studied by Forbes and Rigobon (2002). Note that a high value of this index reflects a strong pressure of speculative attacks on the foreign exchange market (Kaminsky \& Reinhart, 2001). Thus we see that, during the Asian crisis, in addition to Thailand (index value $=54.92$ in December 97), two Latin American countries were selectively affected: Argentina (3.69 in September 02) and Brazil (3.89 in September 02), while all the Asian countries in our sample experienced significant speculative pressures (South Korea has the highest index (1695) in December 97). In addition, the Russian crisis affected mainly Brazil which has the largest index (40.26) and in a less pronounced way Argentina and Turkey. During the subprime crisis (EU: 1.63 in June 08, Italy: 20.46, France: 22.47 and UK: 2.03 in July 07). The periods of crisis show the persistence of the crises studied.

Table 2

Descriptive statistics of index series currency crises

\begin{tabular}{llllllll}
\hline & T & Moy & var & t-stat & Skewness & Kurtosis & J-B \\
\hline Germany & 225 & 4795.55 & 3458648 & 38.679 & -0.109 & 1.44 & $7.782^{*}$ \\
Argentina & 228 & 1.72 & 1.05 & 25.36 & 0.58 & 2.24 & $34.42^{*}$ \\
Brazil & 228 & 1.486 & 1.073 & 21.658 & 0.022 & 0.78 & $9.146^{*}$ \\
Canada & 225 & 1.319 & 0.026 & 122.63 & -0.174 & 2.58 & $8.894^{*}$ \\
South Korea & 228 & 997.907 & 46653 & 69.761 & 0.446 & 0.48 & $11.796^{*}$ \\
United States & 226 & 1.414 & 0.007 & 224.25 & 0.303 & 3.69 & $4.205^{*}$ \\
France & 225 & 33218 & 404272 & 78.366 & 0.837 & 1.26 & $26.710^{*}$ \\
Hong Kong & 228 & 7.766 & 0.00078 & 4194 & 0.079 & 0.98 & $20.567^{*}$ \\
Italy & 225 & 32965 & 137457 & 42.176 & 1.2318 & 0.954 & $60.163^{*}$ \\
Indonesia & 228 & 7347 & 162366 & 27.532 & -0.182 & 2.37 & $29.784^{*}$ \\
Japan & 225 & 116.79 & 170.33 & 134.23 & 0.496 & 3.28 & $13.299^{*}$ \\
Malaysia & 228 & 3.266 & 0.327 & 86.122 & -0.224 & 4.25 & $27.933^{*}$ \\
Mexico & 228 & 39748 & 64593 & 23.615 & 0.6469 & 2.15 & $21.421^{*}$ \\
Russia & 191 & 19.24 & 135.32 & 22.85 & -0.555 & 0.86 & $28.156^{*}$ \\
Singapore & 228 & 1.625 & 0.018 & 181.74 & -0.334 & 3.59 & $12.607^{*}$ \\
\hline Not
\end{tabular}

Note: $\mathrm{T}$ is the number of observations, Moy is the process average, var is the process variance, t-stat is the statistic of student and JB statistic indicates the Jarque-Bera.

The descriptive statistics series show that the average was close to 1 for several series including Canada, Brazil, Argentina, the United States, Turkey and Singapore, but it was stronger for Germany, Mexico and South Korea. The emerging markets are characterized by a higher variance compared with the developed ones. The asymmetry coefficient (skewness) is not zero and negative only for Germany, Canada, Indonesia, Malaysia, Russia, Singapore and Uruguay. The Kurtosis (Kurtosis) is low for all series (below the critical value (3)) indicating the existence of extreme values and the absence of heteroscedasticity in the series (Table 2). According to Table 2, we note that dates break through the RER series almost coincide with currency crises. The DBC index rejects the null hypothesis of unit root with break for all countries except Russia and Venezuela (non-stationary processes avis two breaks). CC is stationary for all countries with a single break.

According to the estimation method of Robinson (1995a), the presence of long memory is verified since estimated parameters are greater than 0 (Table 3) for all series of crisis indices except for France, Malaysia, Mexico and Uruguay. Usually monthly data have a short-term dependency between observations. This can be explained by the strong influence of the aggregation of data on these two semi-parametric methods (GPH and Robinson). The application of the method of Robinson (1995a) in the series examined shows a long-term dependence or persistence of shocks, which verifies the robustness of this method. The results of such methods differ from those heuristics. This verifies the ineffectiveness of these. 
Table 3

Estimated crises indices through long memory process

\begin{tabular}{llllllll}
\hline & GPH1 & GPH2 & GPH3 & ROB1 & ROB2 & ROB3 & Wh \\
\hline Germany & - & - & - & $0.16[2.51]$ & $0.12[2.25]$ & $0.12[2.88]$ & $0.10^{*}$ \\
Argentina & - & - & - & $0.47[7.24]$ & $0.42[7.28]$ & $0.32[7.48]$ & 0.32 \\
Brazil & - & - & - & $0.05[0.77]$ & $0.11[1.92]$ & $0.11[1.92]$ & 0.01 \\
Canada & - & - & - & $0.04[0.54]$ & $0.04[0.68]$ & $0.03[0.60]$ & 0.03 \\
South Korea & - & - & - & $-0.07[-1.02]$ & $0.02[0.35]$ & $-0.04[-0.93]$ & $-0.04^{*}$ \\
United States & - & - & - & $0.05[0.79]$ & $0.08[1.42]$ & $0.12[2.72]$ & $0.08^{*}$ \\
France & - & - & - & $-0.03[-0.38]$ & $-0.15[-2.57]$ & $-0.17[-3.90]$ & $-0.16^{*}$ \\
Hong Kong & $0.98(0.23)$ & $0.94(0.17)$ & $0.94(0.17)$ & - & - & - & 0.80 \\
Italy & - & - & - & $0.18[2.67]$ & $0.212[3.82]$ & $0.21[4.79]$ & $0.19^{*}$ \\
Indonesia & - & - & - & $-0.24[-3.56]$ & $-0.15[-2.61]$ & $-0.05[-1.06]$ & $-0.09^{*}$ \\
Japan & $0.58(0.29)$ & $0.77(0.30)$ & $0.703(0.23)$ & - & - & - & \\
Malaysia & - & - & - & $-0.01[-0.07]$ & $-0.02[-0.29]$ & $-0.01[-0.04]$ & -0.02 \\
Mexico & - & - & - & $-0.11[-1.68]$ & $-0.09[-1.54]$ & $-0.02[-0.34]$ & $-0.05^{*}$ \\
Russia & - & - & - & $0.34[5.20]$ & $0.28[4.94]$ & $0.28[6.44]$ & 0.27 \\
Singapore & - & - & - & $0.019[0.28]$ & $0.02[0.33]$ & $0.06[1.40]$ & $0.03^{*}$ \\
Thailand & - & - & - & $-0.09[-1.36]$ & $-0.04[-0.61]$ & $0.09[2.18]$ & 0.02
\end{tabular}

Note: V is the modified statistic R / S, G1, G2 and G3 are the critical values associated respectively with GPH1, and GPH2 GPH3. The critical values of $\mathrm{V}$ are 1.747- 16.20-10\% and $5 \%$ in the case of one-tailed test. The values of R1, R2 and R3 indicate the values of statistic of Robinson. IC indicates the confidence interval of the ELW estimator.

The presence of long memory at the end of the series shows that there was a real possibility for the persistence of shocks in the index series of speculative pressure. However, the values that are very close to 0.5 lead us to believe that there was enough white noise in the series and the trend was not fully established. It is mentioned by Kim (2001) and Kim and Tsurumi (2000) during the Asian crisis, many exogenous shocks were caused by several factors associated with the crisis, such as speculative attacks, regimes of exchange rates and effects of monetary impact on the stock markets. These intrusive events in the series of crises in the Asian markets indices can affect the long-term dependency in the crisis indices processes ${ }^{3}$.

The Whittle estimator for the series of crisis indices shown in Table 3, presents long memory process $(0<d<0.5)$ for the case of Germany, Argentina, Brazil, Canada, United States, Italy, Russia, Singapore and the UK. The long-term dependency in the crisis period is verified. This may be due to shocks and disruptions related to currency crises. This result seems to be consistent with that of Lee (2000), Nakatsuma (2000), Baig (2001) and Han (2002) demonstrated that the volatility dependence could increase after the crisis using monthly data ${ }^{4}$. Thus, the result indicates that long-term dependence seems to be affected by the shocks that are produced in the foreign exchange markets of the countries studied. This can happen because the invasive occurrences in the exchange market during the crisis lasted for long periods and increased ownership of the long memory of the volatility process. He responded asymmetrically to shocks as pointed Andersen et al. (2002). An interesting question in this

\footnotetext{
${ }^{3}$ Andreou \& Ghysels (2001) found that multiple shocks related to the Asian and Russian financial crises have led to changes in the dynamics of the volatility of the exchange rate before and after impact. Lamoureux \& Lastrapes (1990) showed that shocks over a long period in the series of financial asset prices can lead to structural breaks in the indices studied.

${ }^{4}$ Similar results can be found in several empirical studies to other Asian currencies such as the Thai baht and the Indonesian rupiah. Nakatsuma (2000) showed that among the six daily Asian currencies, the volatility of the exchange rate of the Korean won and Thai baht have particularly proved more persistent after the crisis. Baig (2001) reported that the daily volatility of the exchange rate of Asian currencies experienced sharp increases after the crisis period. In particular, the indices fluctuate from 10 to 20 times during the crisis period compared to the period before the crisis. The big changes in volatility during the crisis seem more severe in South Korea, Thailand and Indonesia because of the low extreme volatility during the pre-crisis period, when exchange rates were all heavily managed to follow US dollar.
} 
study is to understand the relationship between long memory process and the effects of shocks through structural changes.

From estimates of fractional integration parameters by semi-parametric methods, we note that the shocks on indices speculative pressures in countries affected by the Asian crises are more persistent than the series of other countries, which indicates that the contagion of the Asian crisis was more likely than other crises.

After the financial crises of the countries studied, money markets and stock markets have become liberalized. As a result, the foreign exchange market is more closely linked to money markets. Thus, the impact of money markets and foreign stock exchange markets have increased significantly fawn and caused volatility in exchange rates to be more asymmetric in the period after the crisis compared to the period before the crisis (Kim 2001; Caporale et al., 2002). In particular, estimates of fractional integration parameters are higher for countries affected by the Asian crisis of 1997; when the Korean foreign exchange market was almost panic (Classens et al., 2001). In fact, for example, the central bank of South Korea was strongly intervened in the foreign exchange market to defend the Korean won with 5.1 billion dollar, on 8 November 1997; the intervention was completely failed and caused speculation financial and the sharp devaluation of the won (Kim, 2001).

In the empirical illustration, Local Whittle estimator was applied to the economic history of the time series considered by Nelson and Plosser (1982). The fractional integration parameter $m=n^{0.5}$ was estimated, the estimate is different to that of the estimated $d-1$ and the addition of a unit estimated $\hat{d}-1$. This procedure is consistent for $\frac{1}{2}<d<2$ invariant of a linear trend. Table 3 shows the parameter estimates $d$.

For the currency crisis index was used estimator Exact Local Whittle $\hat{d}_{E L W}$ as studied series are nonstationary (2ELW for stationary series). Note that the values of the confidence intervals of the ELW estimator were greater than 1 , which confirms the non-stationary processes.

For the estimator Exact Local Whittle, we proved that the width of the confidence intervals are all less than 9/2. So crises indices series of processes are long memory process. Nelson and Plosser (1982) have shown that through $\hat{d}_{L W}$ approaches unity. This result indicates that the estimator is consistent for Local Whittle $\frac{1}{2}<d<1$. The results of the present study reveals that the estimator Local Whittle is not robust when the value of $d$ can take values in the non-stationary area (greater than $\frac{3}{4}$ ).

The outcome of a semi-parametric estimation procedure is a general proposal for the possibility of nonstationary case. However, this approach has certain drawbacks such as the need to determine the proper order of differentiation and the effects of shocks on the variance. Another approach is to use the exact form or Exact Local Whittle estimator suggested by Phillips (1999a). This estimator was considered by Shimotsu and Phillips (2002) and have the same distribution $N\left(0 ; \frac{1}{4}\right)$ limit for all values of $d$. For the GPH test, we also note the presence of long memory for Hong Kong and Japan, which indicates the persistence of crises for these countries. Finally, according to the 2ELW test, we note the persistence of shocks for these countries also. 


\section{Conclusion}

This study has analyzed the effects of several currency crises on the long-term dependency in the crisis indices process. The estimation results have shown that this dependence was more significant (persistent crisis) during the crises studied in which the foreign exchange markets had experienced significant shocks to the crisis. Thus, long-term dependence in the process of speculative pressure index seems to be the underlying characteristic of invariant temporal aggregation process. Exogenous shocks associated with the crisis seem to affect the long memory effect significantly.

Fazio (2007) interpreted the contagion by increasing the probability of the crisis beyond what could be expected by the links between market factors. In this paper, we have determined the dates of structural breaks in the deterministic component of a set of variables of the countries studied. The test of Lee and Strazicich $(2003,2004)$ has shown which variables that reject the null hypothesis in favor of the alternative of stationarity with rupture. Note that the Asia Pacific region is the most affected by this common bank creditor effect during crises in emerging countries nineties. At the end of this region, Thailand's highest indices were showing the extreme vulnerability of the Thai banking system to a sudden reversal Japanese bank capital. In 1997, when the effect of the resulting contagion of the devaluation of the Thai baht was the strongest, the exchange rates were important values for the main countries affected by the crisis. Finally, vulnerability to contagion channel fell sharply in 2000 for the majority of countries in the sample. Finally, the fragility that contagion channel fell sharply in 2000 for several Asian countries. This is the result of a huge diversification of investment banking major borrowing countries and a better distribution of emerging market funds.

\section{References}

Artus, P. (2000). Crises de pays émergents. Faits et modèles explicatifs, Economica, Paris.

Caramazza, F., Ricci, L. A., \& Salgado, L. (2000). Trade and Financial Contagion in Currency Crises. IMF Working Papers, 55, March.

Caramazza, F., Ricci, L.A., \& Salgado, R. (2004). International contagion in currency crises. Journal of International Money and Finance, 23, 51-70.

Cartapanis, A. (2003). Vers une prévention macro-prudentielle des crises financières internationales. Revue d'économie financière, 70(1), 89-100.

Fazio, G. (2007). Extreme interdependence and extreme contagion between emerging markets. Journal of International Money and Finance, 26(8), 1261-1291.

Flood, R. P., \& Marion, N. P. (1996). Speculative attacks: fundamentals and self-fulfilling prophecies (No. w5789). National bureau of economic research.

Forbes, K. J., \& Rigobon, R. (2002). No contagion, only interdependence: measuring stock market comovements. The journal of finance, 57(5), 2223-2261.

Granger, C. W., \& Joyeux, R. (1980). An introduction to long-memory time series models and fractional differencing. Journal of time series analysis, 1(1), 15-29.

Gravereau, J., \& Trauman, J., (2001). Crises financières, Economica.

Hosking, J. R. (1981). Fractional differencing. Biometrika, 68(1), 165-176.

Hurst, H., (1951). Long term storage capacity of reservoirs. Transactions of the American Society of Civil Engineers, 116, 770-779.

Hurvich, C. M., \& Chen, W. W. (2000). An Efficient Taper for Potentially Overdifferenced Longmemory Time Series. Journal of Time Series Analysis,21(2), 155-180.

Kaminsky, G., Lyons, R., \& Schmukler, S. (2000). Economic fragility, liquidity, and risk: the behavior of mutual funds during crises. unpublished paper, World Bank.

Lee, J., \& Strazicich, M.C., (2003). Minimum LM unit root test with two structural breaks. Review of Economics and Statistics, 85(4), 1082-1089.

Lee, J., \& Strazicich, M.C., (2004). Minimum LM unit root test with one structural break. Working Paper, Department of Economics, Appalachain State University. 
Obstfeld, M. (1995). Risk-taking, global diversification, and growth (No. w4093). National Bureau of Economic Research.

Pritsker, M. B. (2001). The Channels for Financial Contagion, International Financial Contagion. Kluwer Academic Publishers, 67-95.

Radelet, S. \& Sachs, J. (1998). The onset of the East Asian financial crisis. NBER Working Paper, 6680.

Sbracia, M., \& Zaghini, A. (2001). Crises and contagion: the role of the banking system. Marrying the Macro and Micro Prudential Dimensions of Stability, BIS Papers, 1, 241-260.

Selmi, N., \& Hachicha, N. (2010). Long range dependency and forecasting of housing price index and mortgage market rate evidence of subprime crisis published in the proceeding of Conference « Prospective Stratégies et Développement Durable: Quel chemin parcouru? Quelles réponses face aux nouvelles contraintes Économiques et climatiques» (21-23 juin, Hammamet Yasmine (Tunisie)).

Shimotsu, K., \& Phillips, P.C.B. (2006). Exact local Whittle estimation of fractional integration. Annals Statistics, 33, 1890-1933.

Velasco, C. (1999). Gaussian Semiparametric Estimation of Non-stationary Time Series. Journal of Time Series Analysis, 20(1), 87-127. 